\title{
La política británica ante la guerra civil española
}

\author{
EnRIQue Moradiellos
}

En enero de 1939, cuando el colapso republicano en Cataluña anunciaba el final de la guerra civil, Sir Robert Vansittart, Primer Consejero Diplomático del Foreign Office, enjuiciaba en un memorándum interno el efecto de la política británica en el conflicto del siguiente modo:

el curso entero de nuestra política de No Intervención -que en realidad, como todos sabemos, operó de un modo completamente partidista- ha estado favoreciendo la victoria de Franco ${ }^{1}$.

$Y$, ciertamente, es indudable que la inamovible adhesión británica al Acuerdo de No Intervención firmado por los gobiernos europeos en agosto de 1936 tuvo implicaciones diferentes para ambos bandos españoles. En primer lugar, porque dicho Acuerdo prescribía un embargo de armas a los contendientes sin reconocimiento paralelo de sus derechos de beligerancia, constituyendo así un tipo de neutralidad sui generis, que combinaba el respeto jurídico al status del gobierno reconocido con su equiparación a los rebeldes en términos operativos. En segundo lugar, porque esa política neutralista permaneció inalterada a pesar del continuo apoyo italo-germano a los insurgentes, deviniendo así en una tolerancia implícita hacia el sabotaje de la No Intervención practicado por las potencias fascistas.

Habida cuenta del perjuicio que la política británica ocasionó a la República, no es extraño que la izquierda europea en general, y el laborismo en particular, atribuyese la misma a una motivación partidista: la hos-

Memorándum, 16-I-1939. Archivo del Foreign Office, serie 371 (General Correspondence), legajo 24115 , documento W973. En adelante: FO 371/24115 W973. Todos los archivos británicos citados se hallan en el Public Record Office (Kew, Surrey). 
tilidad encubierta de un gobierno británico de mayoria conservadora frente a un gobierno español envuelto en un proceso revolucionario. Por su parte, los medios oficiales británicos siempre rechazaron tal acusación y justificaron su conducta con imponentes motivos de orden internacional: la necesidad suprema de confinar la guerra en España y evitar su conversión en un conflicto europeo. Como veremos, ambos argumentos tienen su parte de razón y puede afirmarse que la formulación y ejecución de la política británica en el conflicto obedeció tanto a una aguda prevención antirrevolucionaria como a la necesidad de adaptarse a los objetivos generales de la política de apaciguamiento europeo.

El papel de la prevención antirrevolucionaria en la génesis de la actitud británica se refleja claramente en la atención prestada por el Foreign Office a la evolución socio-política española durante el quinquenio republicano. El objeto de dicha atención era sobre todo la vigilancia y salvaguardia de los cuantiosos intereses británicos radicados en el país: $1 .^{\circ}$ ) la base naval de Gibraltar, pieza clave para la hegemonía británica en el Mediterráneo y las comunicaciones con la India, cuya seguridad requería como primera condición la benevolencia del hinterland español; $2 .^{\circ}$ ) la destacada participación británica en el comercio exterior de España, puesto que Gran Bretaña absorbía el 25 por 100 de las exportaciones españolas y proporcionaba el 10 por 100 de las importaciones; y $3 .^{\circ}$ ) el gran volumen de las inversiones británicas en el país, que representaban un 40 por 100 de todas las existentes y se concentraban en la minería de piritas y del hierro, sectores de enorme importancia para la industria británica, especialmente la de armamento ${ }^{2}$.

En general, desde la proclamación de la República, el Foreign Office había abrigado serias dudas sobre la capacidad de las autoridades reformistas para estabilizar las agudas tensiones socio-políticas existentes. Sin embargo, fue a partir de febrero de 1936, con la llegada al poder del Frente Popular, cuando comenzó a cobrar forma en los medios oficiales británicos una interpretación precisa de la crisis española, auténtica mimesis de la situación rusa entre febrero y octubre de 1917. A tenor de esta interpretación, España habia entrado en una fase de tipo "Kerenski», con el gabinete republicano progresivamente desbordado por la propia movilización popular que le había encumbrado, registrándose un deslizamiento hacia una situación de doble poder prerrevolucionaria y probablemente fomentada por la Comintern. A la par que se llegaba a esta

\footnotetext{
${ }^{2}$ Véase una exposición ampliada sobre estos intereses en Moradiellos, E., Neutralidad Benévola. El gobierno británico y la insurrección militar española de 1936 (Oviedo 1990), caps. 1 y 2 .
} 
conclusión, el Foreign Office recibió noticias fidedignas sobre una extensa conspiración militar destinada a restaurar el orden, sin otros propósitos de índole fascista, lo que permitía confiar en un desenlace de la crisis que atajase la repetición de la secuencia revolucionaria rusa en la otra esquina del continente ${ }^{3}$.

La cristalización de esta lectura de la crisis española, que tuvo lugar en torno a junio de 1936, fue coetánea con el inicio de la política de apaciguamiento de la Italia fascista, simbolizado por la anulación de las sanciones económicas impuestas a raíz de la invasión italiana de Abisinia. Desde esa fecha, el objetivo primordial de la diplomacia británica consistiría en restaurar la armonía política con Italia en el Mediterráneo, a fin de evitar su alineamiento con los otros dos Estados revisionistas y potencialmente hostiles al imperio británico: la Alemania nazi en Europa central y el Japón en el Extremo Oriente. Este objetivo primordial estaba exigido por la impreparación militar ante una posible guerra en tres frentes dispersos y por el deseo de atajar una carrera armamentista cuyo coste financiero pondría en peligro la incipiente recuperación económica y la estabilidad socio-politica de la metrópoli y del Imperio ${ }^{4}$. Por consiguiente, en vísperas de la tormenta española, la prevención antirrevolucionaria y la búsqueda de una entente mediterránea con Italia eran ya conceptos conjugados en los análisis diplomáticos del Foreign Office.

Desde el inicio de la insurrección militar el 17 de julio de 1936, Londres fue recibiendo noticias sobre el carácter de los bandos en conflicto que concordaban plenamente con sus informes previos. Así, fuentes de la embajada británica certificaron de inmediato que, en España, «hoy no existía ningún gobierno. De un lado estaban actuando fuerzas militares y de otro se les oponia un Soviet virtual». Por su parte, el comandante de Gibraltar advirtió: «Si las fuerzas del gobierno, que son prácticamente comunistas, ganan la partida, puede presentarse peligro para los súbditos británicos» ${ }^{5}$. En consecuencia, el Foreign Office interpretó la sublevación como la fase resolutiva de la prolongada pugna entre fuerzas revolucionarias y contrarrevolucionarias, cuyo choque frontal habia arrumbado al gobierno reformista a la función de mero comparsa impotente y legitimador de las primeras. $Y$ aqui residía la gran diferencia entre el caso

\footnotetext{
${ }^{3}$ Op. cit., págs. 117-133.

${ }^{4}$ ScHmid, G., The Politics and Economics of Appeasement. British Foreign Policy in the 1930s (Leamington Spa 1984). KEnNEDY, P., The Realities behind Diplomacy. Background Influences on British External Policy (London 1981). PratT, L., East of Malta, West of Suez. Britain's Mediterranean Crisis, 1936-1939 (Cambridge 1975).

5 Telegramas del agregado comercial (Biarritz) y del contraalmirante Pipon (Gibraltar), 21-VII-1936. FO 371/20523 W6755 y W6754.
} 
español y el ruso, origen de todos los problemas para la diplomacia británica: la legalidad formal republicana había quedado en el campo donde se desataria la temida revolución social, en tanto que la ilegitimidad formal se encontraba en el campo de la contrarrevolución.

Apenas formulado ese juicio, Londres tuvo que decidir su respuesta ante una petición republicana para que su flota pudiera repostar combustible en Gibraltar y continuar el bloqueo naval que impedia el traslado de las tropas marroquíes a la Península. A la par, el general Franco habia transmitido una demanda opuesta: la neutralización de Gibraltar y la expulsión de la flota gubernamental. El 22 de julio, el gabinete británico decidió que «el gobierno español tenía derecho, por supuesto, a comprar petróleo de fuentes comerciales», aunque "tal circunstancia sería muy indeseable». Por tanto, el Foreign Office quedó encargado de poner en práctica "una política dilatoria por el momento" ${ }^{6}$. En definitiva, el gabinete adoptaba una neutralidad tácita, no proclamada formal y públicamente. Esta política dilatoria, en la medida en que respetaba el status jurídico del gobierno, era una solución provisional entre las dos alternativas existentes ante una guerra civil: $1 .^{\circ}$ ) la asistencia al gobierno reconocido, aceptando la vigencia de sus competencias legales, incluyendo el derecho de su flota a repostar en puertos extranjeros;.$^{\circ}$ ) la neutralidad entre dos beligerantes reconocidos y equiparados en sus derechos y deberes. Y la razón esencial para adoptar una política que descartaba el primer curso y preparaba prudentemente la adopción del segundo era doble: la certeza de que el gobierno no tenía fuerza para frenar la revolución latente en su retaguardia y el deseo de evitar la contingencia de ayudar a un bando cuya legalidad encubria un proceso revolucionario. Así se desprende del telegrama confidencial enviado a las autoridades de los Dominios después de la reunión ministerial:

Informes del cónsul general británico en funciones en Barcelona, donde las fuerzas gubernamentales han aplastado la rebelión, muestran que la situación es crítica dado que el gobierno parece estar a merced de los obreros armados?

Consumada la neutralización de Gibraltar, Londres hubo de afrontar el peligro de internacionalización del conflicto generado por las peticiones

\footnotetext{
${ }^{6}$ Acta del gabinete, 22-VII-1936. Archivo del Gabinete (Cabinet Office Records), serie 23 (Cabinet Minutes \& Conclusions), legajo 85. En adelante: CAB 23/85. Minuta de Mr Seymour, 23-VII-1936. FO 371/20523 W6754.

${ }^{7}$ Telegrama confidencial a los gobiernos Canadá, Australia, Nueva Zelanda, Unión de Sudáfrica y Eire, 23-VII-1936. FO 371/20525 W7223.
} 
españolas de ayuda exterior. No en vano, la perspectiva de un apoyo del aliado francés a la República y de una ayuda italo-germana a Franco planteaba graves amenazas para la política de apaciguamiento. Además, dada la naturaleza del bando republicano, se sospechaba que el apoyo francés potenciaria el comunismo y precipitaria una guerra europea que sólo habría de beneficiar a la Unión Soviética. Sir Maurice Hankey, el influyente secretario del gabinete, ya había advertido a sus colegas el 20 de julio sobre el particular:

En el estado actual de Europa, con Francia y España amenazadas por el bolchevismo, no es inconcebible que dentro de poco nos convenga unirnos a Alemania e Italia. Y cuanto más nos mantengamos alejados de complicaciones europeas, tanto mejor ${ }^{8}$.

Como es bien sabido, el conocimiento de esta opinión británica contribuyó poderosamente a refrenar la inicial disposición del gobierno frentepopulista francés en favor de la República, aunque fue su propia división interna lo que determinó el embargo de armas decretado el 25 de julio. Por el contrario, la actitud británica convenció a Hitler y Mussolini de que una ayuda limitada y encubierta a Franco no encontraría oposición enérgica en Londres y podría reportar notables ventajas políticas y estratégicas ${ }^{9}$. De hecho, la perspectiva de una intervención exterior en la contienda en nada modificó la posición británica, antes al contrario. El 26 de julio, el primer ministro, Stanley Baldwin, dictó a Anthony Eden, secretario del Foreign Office, una directriz política extraordinariamente clara en su simplicidad:

De ningún modo, con independencia de lo que haga Francia o cualquier otro país, debe meternos en la lucha al lado de los rusos ${ }^{10}$.

En consecuencia, cinco días después, Eden implantó secretamente un embargo de armas a la República, a pesar de garantizar en el Parlamento la vigencia del derecho exclusivo del gobierno español a comprar armas en Gran Bretaña. Para entonces, las noticias sobre incautaciones y colec-

\footnotetext{
${ }^{8}$ Memorándum, 20-VII-1936. FO 371/20475 W11340. Hankey era secretario del Gabinete y del Comité de Defensa Imperial desde 1912.

${ }^{9}$ WARNER, G., "France and Non-Intervention in Spain», International Affairs, 38, 1962, págs. 203-220. Young, R., In Command of France. French Foreign Policy and Military Planning, 1933-1940 (Harvard 1978). SAZ, I., Mussolini contra la II República (Valencia 1986). VINAS, A., La Alemania nazi y el 18 de julio (2. ${ }^{a}$ ed. Madrid 1977).

${ }^{10}$ Confidencia de Baldwin recogida por su amigo íntimo y ex-secretario adjunto del gabinete: JONES, T., A Diary with Letters, 1931-1950 (Oxford 1954).
} 
tivizaciones de propiedades británicas en zona republicana habian confirmado los peores presagios y demostrado, en palabras textuales de un funcionario del Foreign Office, "que la alternativa a Franco es el comunismo atemperado por la anarquía" ${ }^{11}$.

En definitiva, a fines de julio de 1936, el juicio sobre la situación española que había dictado la neutralidad tácita se había visto reforzado por cruciales consideraciones de política exterior. En nuestra opinión, la documentación coetánea y posterior, permite afirmar que para esas fechas los gobernantes británicos habian consumado la formulación progresiva y asistemática de una verdadera estrategia política ante un golpe militar devenido en guerra civil. La neutralidad tácita e incondicional era la manifestación externa de dicha estrategia, vertebrada sobre dos factores condicionantes y dos supuestos implícitos.

El primer factor lo constituía la prevención antirrevolucionaria. En consonancia, el temor principal residia en el triunfo de un bando gubernamental anegado por la revolución, tanto por sus efectos sobre los intereses británicos en España como por el peligro de que desencadenase un proceso de bolchevización en Europa. El pavor ante este doble riesgo dictó el completo desahucio del gobierno republicano e hizo preferible la victoria, cuanto primero mejor, de los insurgentes, a fin de conjurar el foco de tensión generado. Esta preferencia se basaba en la convicción de que el movimiento militar era políticamente inocuo, dado su carácter meramente contrarrevolucionario y el predominio del Ejército sobre las fuerzas fascistas. Por igual motivo, la contingencia de una ayuda limitada y encubierta italo-germana no provocó alarma especial ni atemperó el deseo de un triunfo rebelde. En la base de esta relativa tranquilidad se hallaba un supuesto económico sólidamente arraigado en los medios oficiales: la indispensabilidad del mercado comercial y financiero británico para la economía española en la etapa de reconstrucción postbélica. El hecho de que ningún otro país europeo, incluyendo a Italia y Alemania, estuviese en condiciones de financiar esa reconstrucción garantizaba al Reino Unido bases firmes para establecer relaciones cordiales con un régimen militar y contrarrestar influencias contrarias italo-germanas. En último término, si la diplomacia de la libra era insuficiente, siempre quedaba el resorte de la diplomacia de la cañonera: la superioridad de la Royal Navy y su capacidad de bloqueo.

El segundo factor condicionante era la situación interna en Gran Bretaña. La fortaleza sindical y parlamentaria del laborismo (ésta mucho me-

11 The Morning Post, 28-VII. Minuta de Eden, 31-VII. FO 371/20525 W7492. Minuta de G. Jebb, 25-XI-1936. FO 371/20570 W15925. 
nor), unida a la creciente simpatía popular e intelectual por la Repúbilica, constituian límites infranqueables para la política exterior del gabinete, recientemente demostrados durante el conflicto italo-abisinio. Además, la preservación de un alto grado de consenso socio-político era objetivo y requisito del programa gubernamental de recuperación económica y apaciguamiento europeo. Todo ello motivó la prudencia observada en público por las autoridades y, en particular, impidió una demostración de simpatia y apoyo a los rebeldes como la que hubiera supuesto la adopción inmediata de una política de neutralidad oficial. En este sentido, la neutralidad tácita se presentaba como el único expediente disponible, cuya aplicación era solidaria de un supuesto de orden temporal: la expectativa de que la guerra seria breve, dado que las inexpertas y mal abastecidas milicias obreras no podrían contener el avance de un Ejército regular, experimentado y pronto abastecido por dos potencias militares de Europa. Dicho supuesto permitía considerar al neutralismo inconfeso como un refugio provisional, a la espera de que el curso de las hostilidades alcanzase un estadio (por ejemplo, la conquista rebelde de Madrid) que justificase políticamente su conversión en una neutralidad pública.

La estrategia británica esbozada quedó muy pronto amparada por el Acuerdo de No Intervención, cuyo origen estaba en la propuesta de embargo de armas colectivo hecha el 1 de agosto por Francia a todos los gobiernos europeos. En la intención francesa, se trataba probablemente de una fórmula para detener la ayuda exterior a los rebeldes ante su incapacidad propia para auxiliar a la República. Los gobernantes británicos la acogieron como el instrumento idóneo para ejecutar su política y salvaguardar los objetivos diplomáticos establecidos entonces por el Foreign Office. A saber: confinar la guerra en España, refrenando la intervención del aliado francés, evitando el alineamiento con la URSS y eludiendo el enfrentamiento con Italia y Alemania por su apoyo a los rebeldes ${ }^{12}$. De hecho, el Acuerdo firmado a fines de agosto, junto con el Comité de supervisión establecido en Londres, pasaron a constituir el dispositivo óptimo y quizá único para garantizar el cumplimiento de esos objetivos. Además, permitió mantener el embargo tácito británico de modo público y respetable, aplacando las críticas laboristas y ofreciendo al gobierno francés un escudo contra la presión prorrepublicana de sus bases sociales. Por consiguiente, para Londres la política multilateral de No Intervención contenía $a b$ initio el germen de la impostura, en cuanto que su fin

${ }^{12}$ Memorándum de Sargent (subsecretario adjunto responsable del Departamento de Europa central); minutas de Mounsey (idem, Dpto. de Europa occidental) y Eden, 12, 13 y 15Vill-1936. FO $371 / 20534$ W9331. 
real no era el declarado (evitar la intervención exterior) sino la salvaguardia de los objetivos citados con su mera existencia y apariencia de operatividad. Es decir, era el recurso ideal para ejecutar una política definida confidencialmente por Winston Churchill en los siguientes términos:

Considero que lo más importante es hacer que Blum (el premier francés) permanezca con nosotros estrictamente neutral, incluso si Alemania e Italia continúan ayudando a los rebeldes y Rusia envía dinero al gobierno ${ }^{13}$.

Así pues, la No Intervención asumía una función dilatoria crucial en la política británica: cubria con puro bizantinismo diplomático el lapso temporal hasta la conquista insurgente de Madrid, hito clave que justificaría la adopción de una política oficial de neutralidad. Esta función dilatoria quedó demostrada desde finales de agosto, cuando el gabinete británico aceptó tácitamente y sin respuesta conminatoria la continuidad de la ayuda solapada italo-germana a Franco. Muy poco después, con motivo de la decisiva actuación italiana en Mallorca, Londres reiteró esa permisividad siempre que no se franqueasen los umbrales que para entonces habian fijado los estrategas militares británicos: 1. el respeto italiano al statu quo territorial español; y 2. la garantía de que el futuro gobierno español preservaría la benevolencia hacia Gibraltar y, en una posible guerra europea, «seria favorable, o en el peor de los casos, estrictamente neutral» hacia los intereses británicos ${ }^{14}$. Las actas del Comité de Defensa Imperial recogen esta disposición tolerante de modo inequívoco:

Sir Robert Vansittart afirmó que los italianos estaban desempeñando un papel considerable en Mallorca, pero habian dado las garantias más explícitas al Foreign Office de que no tenian intenciones ulteriores. ...En tanto el general Franco continuase con sus victorias, él pensaba que la intervención italiana era improbable ${ }^{15}$.

A tenor de esta declaración se aprecia claramente un aspecto esencial y poco resaltaro de la política británica ante la guerra española: era una

\footnotetext{
${ }^{13}$ Carta de Churchill a Eden, 7-VIII-1936. FO 954/27 (Archivo del FO, serie de correspondencia particular de Eden, legajo 27).

${ }^{14}$ Informe de los Jefes de Estado Mayor: «Mediterráneo occidental: situación originada por la guerra civil española", 24-VIIl-1936. Archivo del Gabinete, serie 24 (Cabinet Papers \& Memoranda), legajo 264. CAB 24/264. También impreso en Documents on British Foreign Policy, 2nd Series, vol. XVIl (London, HMSO, 1979), n. ${ }^{\circ}$ 26. En adelante: DBFP, vol. y n. .

${ }^{15}$ Acta, 8-X-1936. Archivo del Gabinete, serie 2 (Minutes of the Committee of Imperial Defence), legajo 6. CAB 2/6. EI CID era el organismo de coordinación de las politicas de defensa y exterior del Reino Unido. Presidido por el primer ministro, lo componían los ministros responsables de esos departamentos y los jefes de Estado Mayor.
} 
versión específica, si se quiere periférica, de la política general de apaciguamiento europeo. De hecho, la No Intervención británica se conformaría sistemáticamente a los parámetros establecidos por dicha política. En consecuencia, la actuación y presidencia británica en el Comité de supervisión fue un ejercicio continuo de dilaciones y evasivas a la espera de la conquista de Madrid, contingencia que los informes del servicio secreto pronosticaban como segura a corto plazo ${ }^{16}$. Paralelamente, Londres procuró no entorpecer en absoluto las operaciones militares insurgentes y adoptar todas las medidas favorables que fuesen compatibles con la imparcialidad oficial. Por ejemplo, reteniendo al embajador en Hendaya para que actuase como enlace con Burgos, negándose a admitir el bloqueo naval republicano, desalentando operaciones financieras republicanas en bancos británicos y congelando el uso de los fondos generados por la exportación española al Reino Unido. Todo ello bajo la convicción de que el peligro de hostilidad insurgente hacia el Reino Unido estaba mitigado por la clara hegemonia política de los militares y por los resortes previstos por la diplomacia de la libra para la postguerra. El especialista en asuntos españoles del Foreign Office recogió ambas razones en una minuta muy expresiva de octubre de 1936:

Nuestras posibilidades de recuperar la influencia en España durante esta fase (postbélica) son considerables debido a que la revolución española, a diferencia de las revoluciones fascista y nazi, habrá sido ganada esencialmente por los militares, que tienden por tradición hacia el Reino Unido y Francia más que hacia Alemania e Italia. Nuestras posibilidades se incrementarán y facilitarán si nosotros: 1. Adoptamos cuanto antes medidas para demostrar nuestra disposición amistosa hacia el general Franco y su gobierno; 2. Somos capaces de ser útiles al gobierno español en el campo económico y financiero... Por consiguiente, es un interés británico que surja una dictadura militar liberal más que una dictadura fascista: 1. para contrarrestar la influencia italiana y alemana; 2 . para estabilizar la situación interna ${ }^{17}$.

De hecho, hasta octubre de 1936, la estrategia política británica tuvo un éxito notable en el plano diplomático y bilateral anglo-insurgente. Pero

\footnotetext{
${ }^{16}$ El 10 de agosto, dicho servicio había comunicado que la guerra «estaba convirtiéndose en una lucha de rebeldes contra chusma» $y$ «los insurgentes están en mejor posición que el gobierno si éste es incapaz de obtener suministros del exterior». El 14 informaba que, «por consiguiente, una resistencia prolongada (en Madrid) es improbable». Archivo del Ministerio de Guerra (War Office), serie 106 (Directorate of Military Operations \& Intelligence), legajo 1576. Wo 106/1576.

${ }^{17}$ Minuta de Montagu-Pollock, 9-X-1936. Fo 371/20540 W12454. Sobre esas medidas circunstanciales de apoyo a los rebeldes véase Moradiellos, E., op. cit., págs. 261-303.
} 
a partir de entonces, la creciente denuncia laborista de la farsa de No Intervención, junto con la decisión soviética de enviar armas directamente a la República, introdujeron modificaciones transcendentales en el ámbito interno británico e internacional. Sobre todo, la intervención soviética tendría un efecto devastador porque posibilitaría la resistencia republicana en Madrid en noviembre de 1936, destruyendo así la premisa fundamental sobre la que se habia vertebrado la politica británica. Además, esa conversión imprevista del conflicto en una guerra larga se produjo a la vez que Alemania e Italia intensificaban sustancialmente el apoyo militar y diplomático a Franco. Su reconocimiento de iure del gobierno nacionalista, unido al envio de auténticos cuerpos de ejército germano e italiano en noviembre y diciembre, superó por completo el nivel previo de ayuda limitada y encubierta y arruinó el confinamiento de la lucha que había logrado la No Intervención ${ }^{18}$. Todo ello obligó a los gobernantes británicos a reexaminar la situación y practicar reajustes notables en su política española.

El reajuste en el orden bilateral fue bastante rápido. La acción italogermana hacía imposible políticamente conceder la beligerancia y reconocer de facto al gobierno de Franco. Sin embargo, para no obstaculizar el propósito franquista de interceptar los suministros soviéticos con un bloqueo naval, el Foreign Office ideó un sucedáneo transitorio que no implicaba la concesión de los derechos de beligerancia marítimos: el 3 de diciembre una ley aprobada urgentemente prohibió el transporte de armas a España en mercantes británicos desde cualquier origen, encomendando a la Royal Navy la vigilancia de un embargo que sólo afectaba a la República (ya que parte del material soviético era transportado en barcos británicos) ${ }^{19}$. Al día siguiente, 4 de diciembre, después de tres semanas de negociaciones secretas en Burgos, se firmaba un Acuerdo Informal que regulaba las relaciones económicas entre Gran Bretaña y la España insurgente. Con él, se establecieron las bases que posibilitarían una recuperación inmediata del comercio bilateral, permitiendo así competir con la creciente actividad germano-italiana y garantizando el funcionamiento futuro de la diplomacia de la libra. Baste decir que al cabo de

${ }^{18}$ Sobre estos cambios véanse: NaYLoR, J. F., Labour's International Policy: The Labour Party in the 1930s (London 1969). Buchanan, T., The Spanish Civil War and the British Labour Movement (Cambridge 1991). CATTELL, D., Soviet Diplomacy and the Spanish Civil War (Berkeley 1957). HASLAM, J., The Soviet Union and the Struggle for Collective Security in Europe (London 1984). WheAley, R., Hitler and Spain (Lexington 1989). Coverdale, J., La intervención fascista en la guerra civil española (Madrid 1979).

19 Acta de reunión ministerial, 22-X1-1936. CAB 24/265. Memorándum sobre la Royal Navy y la guerra española, marzo 1938. Archivo del Almirantazgo (Admiralty Records), serie 116, legajo 3677. ADM 116/3677. 
un año las exportaciones británicas a zona insurgente sumaban el 75 por 100 de todas las destinadas a España ${ }^{20}$.

El reajuste de la política británica en su dimensión internacional fue más lento y polémico. En diciembre, Eden intentó varias veces que sus colegas reconocieran la necesidad de modificar la conducta previa a tono con la nueva fase de guerra larga y masiva intervención italo-germana. A su juicio, compartido por sus asesores más cercanos en el Foreign Office, los riesgos políticos y estratégicos planteados por esa intervención, sobre todo en Mallorca, se habian convertido en el factor decisivo del problema español, dadas las tendencias expansionistas y potencialmente antibritánicas del nuevo Eje formado por ambas dictaduras. Sin embargo, los ministros desestimaron su interpretación, argumentando que "abstenerse de actuar era importante desde el punto de vista de las negocicciones con Italia» y era suficiente con una reafirmación de la promesa italiana de respeto al statu quo mediterráneo ${ }^{21}$. En consecuencia, como primer paso para restablecer la entente anglo-italiana, el Foreign Office siguió negociando con Roma una declaración conjunta de respeto a los intereses recíprocos mediterráneos: el llamado Acuerdo entre Caballeros hecho público el 2 de enero de $1937^{22}$. No obstante dicho acuerdo, el continuo envio masivo de tropas italianas a España motivó otra tentativa de revisión política por parte de Eden. El 8 de enero de 1937 propuso al gabinete la adopción de medidas resolutivas y conminatorias (por ejemplo, un bloqueo naval de las costas españolas) para mostrar a Hitler y Mussolini la voluntad británica de frenar su actividad en España. En sus palabras:

La guerra civil ha dejado de ser un asunto interno español y se ha convertido en un campo de batalla internacional. El carácter del futuro gobierno de España es ahora menos importante para la paz de Europa que el hecho de que los dictadores no obtengan la victoria en ese país. ...a menos que exijamos un alto en España, tendremos problemas este año en uno $u$ otro de los focos de peligro señalados (Memel, Danzig o

${ }^{20}$ Memorándum: The Anglo-Spanish Clearing , 8-VI-1937. Archivo del Ministerio de Comercio (Board of Trade Records), serie 11 (Commercial Relations \& Treaties Department), legajo 833. BT 11/833. Minuta para Eden, 8-XI-1937. FO 371/21384 W20546. Despacho del embajador (Hendaya), 7-XII-1936. Archivo del F.O., serie 425 (Confidential Prints. Western Europe), legajo 413. FO 425/413.

${ }^{21}$ Memorándum de Eden: Spain. The Balearic Islands, 14-XII. FO 371/20588 W18182. Acta del gabinete, 16-XII-1936. CAB 23/86. Eden reconoció la confianza que se habia tenido en el supuesto de la guerra breve: «Si el general Franco hubiese ganado la guerra con anterioridad, no habrian surgido grandes dificultades como la aventura de Mallorca».

${ }^{22}$ DBFP, XVII, n. ${ }^{\circ} 530$. Coverdale, J., op. cit. , págs. 188-189. 
Checoslovaquia). Consecuentemente, ser firmes en España es ganar tiempo y ganar tiempo es lo que queremos. En esta ocasión no podemos ganar tiempo con dilaciones... Considero imperativo que no escatimemos ningún esfuerzo para detener la intervención en España.

Sin embargo, el gabinete volvió a rechazar la propuesta de Eden por considerarla contradictoria con el objetivo de acercamiento a Italia y porque conllevaba la revisión incipiente de otra premisa básica de la política de apaciguamiento: evitar el alineamiento con la URSS. A este respecto, Sir Samuel Hoare, Primer Lord del Almirantazgo, rechazó los temores a un triunfo franquista con el argumento de que «había otros, incluyendo quizá algunos miembros del gabinete, que querian a toda costa que los soviéticos no triunfasen en España» ${ }^{23}$.

En esencia, el desacuerdo sobre el peligro presente en España era resultado de la divergencia creciente sobre la viabilidad de la política de acercamiento a Italia y el modo de aplicarla. Eden consideraba que había de practicarse desde una posición de fuerza, a fin de no aumentar el prestigio de Mussolini y su tentación de aliarse con Berlín para obtener la hegemonía mediterránea. Por el contrario, sus colegas estimaban que el apaciguamiento de Italia era factible dada su debilidad económica y el conflicto entre sus ambiciones y las alemanas en Austria y los Balcanes. En este dilema, la guerra española era o bien un campo de prueba de la bona fides italiana o bien un obstáculo marginable que no debía interferir en la política trazada. En todo caso, la divergencia fue subsanada provísionalmente el 9 de enero de 1937, cuando el gabinete aceptó un programa de acción diplomática elaborado por Eden que representaba un compromiso entre sus frustradas propuestas y la inhibición a ultranza. El Foreign Office intentaria detener la escalada intervencionista mediante presión directa sobre Roma y Berlín y a través del Comité de No Intervención, al que se propondría prohibir la salida de voluntarios extranjeros hacia España y adoptar urgentemente un plan de control realizable de las fronteras y costas españolas. Así pues, el reajuste político británico concluía con la decisión de intentar hacer efectiva la No Intervención, respetando los parámetros generales de la política de apaciguamiento. El carácter inviolable de estos parámetros fue reforzado por el siguiente juicio estratégico emitido por los Jefes de Estado Mayor: "en ninguna circunstancia deberíamos luchar para que los italianos no ocupen Baleares,

${ }^{23}$ Acta del Comité de Política Exterior, 8-1-1937. Archivo del Gabinete, serie 27 (Committee on Foreign Policy), legajo 628. CAB 27/628. Dicho comité constituía un mini-gabinete compuesto por los principales ministros, encargado de preparar los asuntos de politica exterior a decidir por el gabinete en pleno. 
puesto que no era un interés vital para nosotros como lo era para los franceses» ${ }^{24}$.

A pesar del estrecho margen de maniobra disponible, los esfuerzos de la diplomacia británica, bajo el impulso de Eden, lograron una pausa en la ofensiva intervencionista italo-germana. Ni Hitler ni Mussolini deseaban forzar más de lo necesario la permisividad británica y tampoco estaban dispuestos a que su ayuda a Franco precipitara una guerra prematura. En consecuencia, abandonaron el obstruccionismo y aceptaron las propuestas para convertir la No Intervención en una realidad práctica. A mediados de febrero de 1937, el Comité prohibió la salida de voluntarios extranjeros con destino a España y aprobó un plan de control que entraría en vigor dos meses después ${ }^{25}$. Desde entonces, las fronteras francesa y portuguesa con España quedaron vigiladas por observadores internacionales que también embarcaban en los mercantes europeos dirigidos a puertos españoles. Completando el control, las flotas británica y francesa se encargaron de patrullar la costa insurgente mientras las flotas italiana y germana hacían lo propio en la costa republicana.

La distensión lograda así en el ámbito internacional posibilitó que Eden intentase de nuevo un pronunciamiento firme del gabinete en otro contencioso pendiente: la requisa insurgente de piritas propiedad de compañías británicas y su exportación a Alemania e Italia para compensar la ayuda recibida. A primeros de marzo, basándose en la necesidad de garantizar el suministro de ese mineral estratégico y la resistencia insurgente a un compromiso, Eden propuso que la Royal Navy interceptase los barcos cargados con piritas requisadas. Sin embargo, el gabinete desestimó esa demostración de fuerza naval ante Franco al igual que la había rechazado ante Italia y Alemania. El ministro de Hacienda, Neville Chamberlain, que sucedería a Baldwin como primer ministro dos meses después, encabezó la oposición a Eden con una defensa enérgica de la conveniencia de esperar a la postguerra para poner en vigor la diplomacia de la libra:

Había que recordar que no estábamos tratando sólo con los insurgentes españoles sino también, tras de ellos, con los alemanes e italia-

${ }^{24}$ Acta, 9-1-1937. CAB 27/628. Acta de la Junta de Jefes de Estado Mayor, 11-1-1937. Archivo del Gabinete, serie 53 (Minutes of the Chief of Staff Sub-Committee), legajo 6. CAB $53 / 6$.

${ }^{25}$ Sobre la cautela italo-germana véase: Documents on German Foreign Policy, Series D, vol. III (Germany and the Spanish Civil War) (London 1951), n. ${ }^{\circ} 197,200$ y 215 . En adelante: DGFP y n. Ciano's Diplomatic Papers (London 1948), págs. 85-87. Sesiones del Comité de No Intervención, 16-II y 8-III-1937. Archivo del Comité de No Intervención, legajos 1 y 27. FO $849 / 27$ 
nos. El general Franco no era un agente libre. Sin duda que esperaba triunfar, pero dificilmente sin la ayuda italiana y alemana... Por tanto, insistir en la propuesta no sólo era inútil sino que llevaria a una situación muy grave con Alemania e Italia. Sin embargo, suponiendo que Franco hubiese ganado la guerra civil, la situación sería muy diferente porque entonces se encontraría buscando la ayuda de otros paises además de la de Alemania e Italia. Ese sería el momento de ejercer fuerte presión sobre él. ...ése sería el momento para actuar ${ }^{26}$.

La derrota de Eden en este asunto fue completa, aunque el gabinete le autorizó a presentar una protesta enérgica en Burgos y, de ese modo, obtuvo la garantía de que el suministro de piritas a Gran Bretaña no se interrumpiría por las requisas (como en efecto así fue). Sin embargo, un mes después de esa derrota, en abril de 1937, Eden consiguió la aprobación del gabinete para una demostración de fuerza en el más puro estilo de la diplomacia de la cañonera. Su origen estaba en el bloqueo naval de Bilbao impuesto por Franco, complemento indispensable de su nueva estrategia de eliminación gradual del frente norte una vez estancada la ofensiva sobre Madrid. Debido a la falta de derechos de beligerancia marítimos, el bloqueo sólo podía ejercerse dentro de las tres millas jurisdiccionales españolas; un límite estrecho para capturar los mercantes que intentasen burlar el bloqueo y fácil de vigilar por la defensa costera republicana. En consecuencia, Franco trató de forzar el reconocimiento de beligerancia mediante el ejercicio del bloqueo en aguas internacionales, negándose a admitir una oferta británica para llegar a un compromiso mutuamente aceptable. Este hecho, unido a la presión de la opinión pública, obligó al gabinete a conceder protección naval a los mercantes británicos hasta las tres millas. La flota insurgente hubo de claudicar así ante la enorme superioridad de la Royal Navy y cesar sus actividades en alta mar, al menos respecto al tráfico británico. En privado, Eden comentaria: «Este gobierno sería más reaccionario (en su política española) si yo no estuviera en él» ${ }^{27}$.

La politica de firmeza alentada por Eden en los planos diplomático y bilateral tenía como corolario la creación de las condiciones propicias para un armisticio y mediación en el conflicto. A su juicio, compartido por

${ }^{26}$ Memorándum de Eden; Nota de Hoare; 1 y 3-1II. CAB 24/268. Acta del gabinete, 3-III1937. CAB 23/87. Cfr. SMYTH, D., «The Moor and the Money-lender: Politics and Profits in Anglo-German Relations with Francoist Spain, 1936-1940", en M.L. Recker (ed.), From Competion to Rivalry (Stuttgart 1986), págs. 143-174.

${ }^{27}$ Actas del gabinete, 7, 11, 14, 19 y 21-IV-1937. CAB 23/88. CABLE, J., The Royal Navy and the siege of Bilbao (Cambridge 1979). The Diplomatic Diaries of Oliver Harvey, 19371940 (London 1970), pág. 40. Harvey era secretario particular de Eden en el Foreign Office. 
el gabinete, ésa sería la solución ideal para el problema español y la más ventajosa para los intereses británicos. Por eso, en abril y mayo de 1937, el Foreign Office sondeó la disposición de las potencias europeas al respecto, a la par que defendia el libre tráfico en alta mar y presentaba al Comité de No Intervención un plan para la evacuación de España de los combatientes extranjeros (denominados oficialmente "voluntarios» para equiparar las tropas fascistas con los brigadistas internacionales) ${ }^{28}$. Sin embargo, las previsiones de Eden se vinieron abajo en el verano de 1937, con la retirada germano-italiana de la patrulla naval y la consiguiente suspensión del control de las costas y fronteras. La iniciativa italo-germana, un verdadero ejercicio de tanteo sobre la permisividad británica, pretendia interrumpir el debate sobre la evacuación de "voluntarios» y forzar la concesión de la beligerancia a Franco en sustitución de la patrulla naval ${ }^{29}$.

La reacción británica ante el colapso virtual de la No Intervención efectiva fue muy prudente, bajo la premisa de que "nuestro objetivo primordial es evitar el deterioro de nuestras relaciones con Alemania e Italia». El gabinete decidió mantener vigente a toda costa el Comité de No Intervención «a fin de proporcionar la apariencia de acuerdo internacional». Para ello, el Foreign Office presentó al Comité el llamado Plan Británico del 15 de julio, que contemplaba la concesión de la beligerancia a los bandos españoles cuando hubiese comenzado la evacuación de voluntarios. Esa propuesta de compromiso fue aceptada como «base de discusión» por Hitler y Mussolini, conscientes de que significaba el retorno a la situación bizantina anterior a enero de 1937 y el fin práctico del control de No Intervención ${ }^{30}$.

La retirada británica en el frente diplomático fue seguida de un agravamiento de la tensión internacional en agosto, a causa de la ayuda italiana al bloqueo insurgente. Con objeto de cortar los envíos soviéticos, submarinos italianos comenzaron a operar en todo el Mediterráneo contra el tráfico destinado a puertos republicanos. En el plazo de un mes, al menos once mercantes y un destructor británicos fueron atacados en alta mar por submarinos supuestamente «piratas». En esas circunstancias, Eden convenció al gabinete de que la acción italiana excedia los márgenes de tolerancia admisibles y que el prestigio e interés británicos exigían

${ }^{28}$ Actas del gabinete, 28-IV y 5-V-1937. CAB 23/88. DBFP, XVIII, n. ${ }^{\circ} 482$. Sesión del Comité, 26-V-1937. FO 849/1.

${ }^{29}$ Coverdale, J., op. cit., págs. 274-276. DGFP, n. ${ }^{\circ} 360,366$ y 371. Weingerg, G., The Foreign Policy of Hitler's Germany (Chicago 1980), vol. Il, págs. 99-102 y capitulo V.

${ }^{30}$ Actas del gabinete, 30-VI y 7-VII-1937. CAB 23/88. Sesión del Comité, 16-VII-1937. FO 849/1. DGFP, n. ${ }^{\circ} 375,376$ y 396. 
actuar en defensa del libre tráfico en el Mediterráneo. El resultado fue la Conferencia de Nyon de septiembre de 1937, en la que todos los países ribereños, con la ausencia italiana, decidieron encomendar a la flota anglo-francesa la patrulla del Mediterráneo para terminar con los ataques piratas ${ }^{31}$. Las resoluciones de Nyon mostraron claramente a Italia los limites de la permisividad británica y pusieron fin a las operaciones navales fuera del teatro español.

Sin embargo, Nyon fue la última vez que el gabinete secundó la política de firmeza de Eden en el asunto español. A partir de entonces, la necesidad de reajustar esa política ante el fracaso de la No Intervención efectiva fue agravando la divergencia latente desde enero tanto en el gabinete como en el propio Foreign Office.

Durante los meses finales de 1937, Eden reiteró su tesis de que la intervención en España constituia el campo de prueba de la bona fides italiana respecto a Gran Bretaña. Sobre todo, en vista de la cristalización del Eje con la visita de Mussolini a Berlín y del proceso de fascistización que estaba registrándose en la España insurgente, con sus crecientes alusiones a la recuperación de Gibraltar ${ }^{32}$. Por ello, la apertura de negociaciones para un acuerdo anglo-italiano debia condicionarse, como mínimo, a una retirada de las tropas italianas de Baleares y al apoyo fascista al plan de evacuación de voluntarios debatido en el Comité de No Intervención. Mientras tanto, el interés británico exigía la prolongación de la guerra y abstenerse de presionar al gobierno francés para que cerrase su frontera al contrabando de armas republicano. El 29 de septiembre declaró en el gabinete:

Es evidente que no nos interesa que el final de la guerra llegue con rapidez, puesto que una victoria total y pronta de Franco incrementaría enormemente el prestigio de Italia ... Un triunfo rápido en España haría que Alemania e Italia se volviesen intratables a efectos de negociación y quizá peligrosos en otras direcciones... Debemos confiar en que los chinos en Asia oriental y el gobierno español en el Mediterráneo puedan

${ }^{31}$ Reunión de ministros, 17-VIII y 2-IX; Acuerdo de Nyon, 11-IX-1937. DBFP, XIX, n. ${ }^{\circ} 94$, 114 y 156. Memorándum del Almirantazgo, marzo 1938. ADM 116/3677. ALPERT, M., La guerra civil española en el mar (Madrid 1987), págs. 288-289.

32 WeINBERG, G., op. cit., págs.274-283. El embajador y primer secretario en Hendaya remitieron dos despachos (23-1X y 13-X-1937) advirtiendo que la prolongación de la guerra estaba generando un nacionalismo totalitario en la España franquista, inquietante para Gibraltar. El segundo subrayaba que parecia que «España era sólo otra etapa italiana en la puesta en práctica de la política de Mare Nostrum comenzada con el ataque a Abisinia". Ambos fueron impresos y el segundo remitido a los ministros por orden de Eden. FO 425/ 414. 
ofrecer una resistencia duradera; y aunque nosotros no estemos dispuestos a proporcionarles ninguna ayuda efectiva, desde luego que no debemos debilitarles... Tal política de no hacer nada que acelere la victoria nacionalista no se contradice con el propósito de eliminar las causas de fricción entre nosotros e Italia sobre la base del respeto mutuo.

Sin embargo, sus tesis fueron impugnadas por los restantes ministros. En el plano estratégico, los jefes de Estado Mayor reiteraron la prioridad de una entente mediterránea con Italia y dictaminaron que «no hay razones fuertes estratégicas para exigir la evacuación de Baleares del personal italiano" y "sería más seguro limitarse a pedir una reafirmación (del respeto a la integridad española)». En el orden político, Chamberlain subrayó la urgencia de iniciar cuanto antes las conversaciones con Italia porque había posibilidad de separarla de Alemania y «ésto era tan importante para la paz que merecía la pena correr algunos riesgos». El dilema planteado se solucionó al aprobar el gabinete un curso político intermedio, definido por Lord Halifax, Lord Presidente del Consejo, del siguiente modo:

Nuestro primer esfuerzo sería intentar que Mussolini retirase los voluntarios italianos. Era improbable que pudiese acceder a ello. Entonces deberiamos inducirle a que no enviase más voluntarios y a que reafirmase las garantías que ya había dado respecto a sus objetivos últimos. En síntesis, deberiamos intentar lograr todo lo posible en el segundo punto, con vistas a tranquilizar a Francia ${ }^{33}$.

Eden, a pesar de mantener su reserva, asumió la decisión ministerial y procuró ejecutarla en los meses sucesivos. La eliminación del frente norte fue aprovechada para negociar un intercambio de agentes diplomáticos con Burgos en noviembre de 1937, una medida que supuso el reconocimiento del gobierno franquista como gobierno de facto en España. El propósito era contrarrestar la influencia del Eje en Burgos y preparar los resortes previstos por la diplomacia de la libra para la postguerra, aunque públicamente se justificó «con argumentos comerciales más que políticos en vista de las críticas de la izquierda en Gran Bretaña» ${ }^{34}$.

Paralelamente, el Foreign Office propuso a Roma conversaciones tripartitas con Francia para solucionar el problema de los voluntarios y uha-

\footnotetext{
${ }^{33}$ Nota de Eden para leer en el gabinete, 2-IX. FO 371/21401 W17119. Acta del gabinete, 29-IX. CAB 23/89. Informe de los Jefes de Estado Mayor, 29-IX-1937. DBFP, XIX, n. 209.

${ }^{34}$ Memorandos sobre relaciones con Franco, 17-VIII y 5-XI-1937. FO $371 / 21299$ W15799 y FO 371/21401 W20397. Minuta sobre aspectos juridicos, 23-XI-1937. FO 371/21402 W20727. La frase citada es de Chamberlain (24-XI-1938). FO 371/22657 W16097.
} 
cer realmente efectiva la política de No Intervención». Como el gabinete había anticipado, la respuesta italiana (9 octubre) fue negativa, remitiendo el asunto al Comité y anunciando que no participaría en conversaciones en las que no estuviera presente Alemania. Ante ese fracaso, el gobierno francés solicitó la conformidad británica para abrir su frontera al paso de armas con destino a la República. Pero, a pesar del esfuerzo de Eden, el gabinete resolvió negar esa conformidad expresamente y aceptar la propuesta italiana de seguir las deliberaciones en el Comité. Chamberlain defendió esta política con el siguiente argumento:

Puede que el momento actual sea de importancia crucial para Europa y bien pudiera ser que el futuro del Mediterráneo dependiese de cómo se resolviera. Posiblemente, nosotros teníamos la clave en el asunto porque el gobierno francés, aunque ahora estuviese bajo la influencia del pánico, sin duda atribuía gran importancia al mantenimiento de buenas relaciones con nosotros. Por tanto, el gobierno francés haría bastantes concesiones a fin de acomodarse a nuestro punto de vista ${ }^{35}$.

$Y$, efectivamente, dada la oposición británica, Paris decidió mantener cerrada su frontera y seguir debatiendo el asunto en el Comité. Por su parte, Roma trató de amortiguar su negativa con una actitud menos obstruccionista en el Comité, cuyo resultado fue la aprobación por el mismo de un complicado plan de evacuación de voluntarios en noviembre de $1937^{36}$. Aun así, la divergencia entre Eden y sus colegas sobre el perfil de la política española no dejó de incrementarse hasta llegar a su punto culminante en febrero de 1938.

A mediados de ese mes, bajo la sombra de la inminente anexión nazi de Austria, Mussolini solicitó a Londres la apertura urgente de negociaciones para un acuerdo bilateral que incluyese el reconocimiento británico del imperio italiano en Abisinia. Eden, sospechando que Roma deseaba compensar con un éxito diplomático su abandono de la independencia austriaca, propuso al gabinete que se condicionara esa apertura a "una indicación de buena fe italiana» en España. A su juicio, la colaboración en la retirada de voluntarios seria la prueba de que Roma deseaba un acuerdo leal y no perseguia la instalación de un régimen español favorable a sus proyectos de hegemonia mediterránea y aliado en caso de guerra. Por el contrario, Chamberlain, entendiendo que Mussolini trataba de recuperar su política de equidistancia entre Berlín y Londres,

${ }^{35}$ Actas del gabinete, 13 y 20-X-1937. CAB 23/89. Telegramas del embajador en París, 25-X-1937. FO 371/21347 W19609 y W19656.

${ }^{36}$ Sesión del Comité, 4-XI-1937. FO 849/1. 
propuso la apertura inmediata de negociaciones y seguir marginando el asunto español como hasta entonces. Tanto Eden como Chamberlain compartían la premisa de que "no es posible ningún apaciguamiento duradero en el Mediterráneo hasta que la úlcera española sea cicatrizada». Sin embargo, mientras Eden pretendía cicatrizarla con la retirada italiana y la mediación, Chamberlain estaba dispuesto a condonar la intervención italiana y asumir la consecuente terminación de la guerra con la victoria de Franco. El resto del gabinete secundó al primer ministro y, por tanto, Eden dimitió el 20 de febrero de 1938, siendo sustituido por Lord Halifax como secretario del Foreign Office. Ello no obstante, el impacto de la dimisión de Eden en la opinión pública y el Parlamento forzó una concesión importante de Chamberlain: el posible acuerdo anglo-italiano habría de incluir "una solución de la cuestión española» ${ }^{37}$.

Asi pues, el Foreign Office inició las conversaciones para el acuerdo bajo la condición de que éste incluiría una «solución de la cuestión española». Chamberlain rehusó definir exactamente el significado de esa condición, sin embargo el secretario privado de Lord Halifax anotó en su diario que significaba: «cuando Franco haya vencido». De hecho, en marzo y abril de 1938, el gabinete británico pensó que la victoriosa ofensiva franquista en Aragón estaba a punto de eliminar por sí misma la cuestión española. En consecuencia, el 16 de abril se concluyó el Acuerdo AngloItaliano que, entre otras cosas, prescribia el reconocimiento del imperio abisinio y la renovación por Italia de la garantía de respeto a la integridad española y su promesa de retirar los voluntarios italianos «al término de la guerra civil». La entrada en vigor del Acuerdo, sin embargo, quedaba aplazada hasta que se hubiese alcanzado la condición impuesta por Londres: "una solución de la cuestión española» ${ }^{38}$.

${ }^{37}$ Con Eden dimitió Lord Cranborne, subsecretario parlamentario del FO. Vansittart, que compartia las tesis españolas de Eden, ya había sido promovido/relegado a Primer Consejero Diplomático. Memorándum del FO, 25-X-1937; Notas del diario de Chamberlain y Acta del gabinete, 19-1I-1938; Telegrama de Lord Halifax al embajador en Roma, 21-II-1938. DBFP, $\mathrm{XIX}, \mathrm{n} .{ }^{\circ} 269,568,573$ y apéndices I y II. Eden, A., The Eden Memoirs. Facing the Dictators (London 1962), págs. 579-592. Ciano's Diplomatic Papers, págs. 164-184.

${ }^{38}$ The Diplomatic Diaries of Oliver Harvey, pág.124. Lord Halifax informó al gabinete (16|1|-1938) que "las fuerzas del gobierno español estaban siendo completamente derrotadas». El 30 comunicó que "las conversaciones con el gobierno italiano van bien" y uestaremos en condiciones de aprovechar esta libertad de acción tan pronto como la situación en España lo permita». El 13 de abril reconoció que «el supuesto contemplado en el canje de notas era que la guerra española hubiera terminado». CAB 23/92 y 93 . Cfr. el editorial de The Times (9-VII-1938): «Al firmarse el Acuerdo en Roma, ambas partes tenian la impresión de que "la solución en España" era inminente y seria aportada por la victoria del general Franco». 
Desgraciadamente para el gobierno británico, el supuesto de la victoria de Franco contemplado en el Acuerdo resultó ser prematuro. El 16 de marzo de 1938, el nuevo y breve gobierno de Blum en Francia había abierto secretamente la frontera al paso de armas soviéticas que posibilitarían la resistencia republicana. Tras la caída de ese gobierno (8 de abril), el esfuerzo del Foreign Office se centró en lograr que el gobierno de Daladier cerrase la frontera al tráfico de armas. De hecho, tras la dimisión de Eden, la política británica ya no consistía en esperar más o menos impasiblemente la derrota militar republicana sino que implicaba acelerar en cuanto estuviera a su alcance esa solución, a fin de permitir la entrada en vigor del Acuerdo y el apaciguamiento de Italia. Bajo la convicción de que «la ayuda francesa está retrasando, nadie sabe por cuánto tiempo, cualquier solución posible en España», Londres ejerció una presión constante sobre el gobierno francés para que cerrase la frontera y dejase de prolongar la guerra ${ }^{39}$. A principios de junio de 1938 , aprovechando que la creciente crisis germano-checa incrementaba el valor de la alianza británica para Francia, el Foreign Office decidió forzar una decisión en París. El embajador británico comunicó al ministro francés de Asuntos Exteriores que su gobierno «no comprendía por qué el gobierno francés era incapaz de cortar el paso de armas en la frontera con Barcelona. Seria una gran desgracia que por este motivo decayese la simpatía con Francia en Gran Bretaña». Como resultado indudable de esta gestión, París cerró la frontera el 13 de junio, eliminando la vía esencial de suministros republicanos y dejando éstos al albur del bloqueo naval franquista. Ello no obstante, a fines del mismo mes, el embajador reiteró su advertencia al propio Daladier para evitar la reapertura de la frontera ante el recrudecimiento de la intervención italiana. En esa ocasión, transmitió «la importancia vital que el gobierno británico atribuye al cierre permanente de la frontera pirenaica». $Y$ añadió que era necesario «mantener esa frontera infernal cerrada» y evitar que los rusos siguieran enviando material a la República porque «si lo consiguen la guerra se prolongaría por muchos meses" ${ }^{40}$.

${ }^{39}$ Telegramas del embajador en Paris, 15, 16 y 17-1II-1938. FO $371 / 22659$ y 22639 W3363, W3424, W3484 y W3491. Minutas de Mounsey y Sir Alexander Cadogan (Subsecretario Permanente del F.O.), 8-IV-1938. FO 371/22642 W4718. Acta de las conversaciones anglo-francesas, 28 y 29-IV-1938. FO 371/21591 C3687.

40 Telegramas del F.O. al embajador en Paris y viceversa, 7 y 8-VI-1938. FO 371/22659 W7332 y W7352. Carta del embajador a Lord Halifax, 29-VI-1938. FO 800/323. Archivo del F.O., serie 800 (Private Collections), legajo conteniendo la correspondencia privada de Lord Halifax. 
Así pues, como apuntó en su diario el secretario de Lord Halifax: «El gobierno está rezando por la victoria de Franco" ${ }^{41}$. Por ello, se abstuvo de responder enérgicamente a los ataques aéreos franquistas contra el tráfico mercante con la República, contentándose con protestas diplomáticas y pedir a Roma que moderase el número de ataques y su incidencia sobre buques británicos. Igualmente, el abandono de toda esperanza de hacer efectiva la No Intervención se demostró en el hecho de que el Comité sólo se reuniera una vez durante 1938: en julio y únicamente para aprobar un complejo plan de evacuación de voluntarios absolutamente impracticable. Naturalmente, esta política seguía teniendo como base la confianza en la diplomacia de la libra para el futuro. Lord Halifax lo recordó al gabinete el 27 de julio:

Alemania e Italia habian hecho grandes cosas por España, pero después de la guerra lo que España necesitará será dinero y ésto sólo lo tenía el Reino Unido. Por tanto, ellos serían los únicos beneficiarios de la guerra ${ }^{42}$.

La convicción del gabinete de que los riesgos implícitos en la victoria franquista no eran tan graves como Eden había predicho se vio aparentemente corroborada por la conducta de Franco durante la crisis de septiembre que desembocaría en el Acuerdo de Munich y el reparto de Checoslovaquia. Los estrategas británicos habian previsto que en caso de guerra la España de Franco seria favorable a Alemania y proporcionaría ayuda logística a su flota. Sin embargo, el 27 de septiembre, mientras Londres y París se aprestaban con reticencia a combatir si Hitler rechazaba su oferta de compromiso, Franco informó a ambos gobiernos que mantendría «una actitud de completa neutralidad» ${ }^{43}$. La solución de la crisis en Munich evitó que Franco tuviera que poner a prueba su intención y también evitó que Londres tuviese que comprobar la viabilidad de su propósito de mantener aislado el conflicto español aun en caso de guerra por Checoslovaquia. De todos modos, la conferencia de Munich y el papel

${ }^{41}$ The Diplomatic Diaries of Oliver Harvey, pág. 148.

${ }^{42}$ Acta del gabinete, 27-VII-1938. CAB 23/94. Halifax repetía la opinión del embajador alemán en Paris. Sobre la pasividad ante los bombardeos, véanse las actas del gabinete (29-VI y 6-VII). CAB 23/94. Nota de Lord Halifax para Chamberlain, 9-VI-1938. Archivo del Primer Ministro (Prime Minister's Office), serie 1 (Correspondence \& Papers), legajo 360. PREM 1/360. Sesión del Comité, 5-VII-1938. FO 849/1.

${ }^{43}$ Nota del ministro para la Coordinación de la Defensa: Apreciación de la situación en caso de guerra con Alemania, 14-IX-1938. CAB 24/278. Telegramas del agente británico en Burgos, 23, 27 y 28-IX-1938; minutas de Mounsey y Cadogan, 28-IX-1938. FO 371/22698 W13084, W12929, W13030 y W13118. 
de Mussolini en ella reforzaron enormemente la determinación británica de eliminar el obstáculo español que impedía la reconciliación con Italia.

A mediados de octubre, el Foreign Office dictaminó que la neutralidad de Franco «era una clara indicación de que no permitiria ser dominado por potencias extranjeras» y «eliminaba cualquier temor francés sobre su frontera sur». En esas condiciones, «El gobierno de Su Majestad debería separarse categóricamente de cualquier intento de solución de los asuntos internos españoles" y abandonar cualquier idea de mediación ${ }^{44}$. Atendiendo a estos principios, el 2 de noviembre de 1938 el gabinete anunció la entrada en vigor del Acuerdo anglo-italiano, argumentando que después de Munich era evidente que el conflicto español «había dejado de ser una amenaza para la paz de Europa» y, por tanto, ya se había cumplido la condición de hallar «una solución a la cuestión española». Lord Halifax reconoció implícitamente que ello significaba aceptar la victoria franquista al declarar en la Cámara de los Lores:

Desde el principio de las conversaciones entre el gobierno británico y el italiano, Mussolini siempre había dejado claro que, por razones de todos conocidas, tanto si las aprobábamos como si no, no estaba dispuesto a consentir la derrota del general Franco ${ }^{45}$.

Esta decisión del gabinete fue duramente criticada por la oposición laborista y por los conservadores más sensibles a la amenaza del Eje, entre ellos Eden, que atribuyó el deterioro de la situación internacional a la falta de firmeza británica en España. En enero de 1939, el éxito de la ofensiva franquista en Cataluña permitió que la tesis de Eden encontrase eco renovado en los círculos oficiales. Tres días antes de la caída de Barcelona, Sir Robert Vansittart y el ministro de Comercio presionaron fuertemente al gabinete para revisar su conducta. A juicio de ambos, el creciente expansionismo del Eje hacía muy peligrosa una rápida victoria de Franco y aconsejaba eliminar el veto a la ayuda francesa para posibilitar la resistencia republicana. Sin embargo, la mayoría del gabinete compartió la tesis de Chamberlain de que «cuanto primero terminase la guerra en España más oportunidades habia de mejorar las relaciones italo-francesas». Además, en el peor de los casos, la destrucción provocada por la lucha impediría que Franco «estuviese en posición de ser una molestia para nadie», mientras que «nuestra supremacia naval en el Medi-

${ }^{44}$ Memorándum de Mounsey, 21-X-1938. FO 371/22655 W14422.

${ }^{45}$ Parliamentary Debates. House of Lords, 3-XI-1938, col.1624. Acta del gabinete, 26-X1938. CAB 23/96. 
terráneo haria que Italia no pudiese hacer nada efectivo contra nosotros o contra Francia». En esas condiciones, el gabinete ratificó la política española seguida, con la salvaguardia de que, a fin de no excitar las críticas de la oposición, «debíamos evitar cualquier muestra de satisfacción ante la perspectiva de una victoria de Franco» ${ }^{46}$.

Tras la conquista de Cataluña, y siguiendo la política de pasividad expectante, el Foreign Office se dispuso a preparar el reconocimiento de iure del gobierno franquista. Sólo en un caso, a principios de febrero de 1939, se permitió una notable intervención diplomática en el conflicto. A petición de Franco, Londres autorizó que un buque británico llevase un emisario nacionalista a Menorca para proponer a los republicanos la rendición a cambio de ser evacuados a Francia en el mismo buque. La posición estratégica de la isla, junto con las garantías de Franco de que seria ocupada sin fuerzas italianas o alemanas, hicieron posible esta intervención británica en la rendición pacífica de Menorca ${ }^{47}$. Sin embargo, la medida no se repitió en las semanas siguientes, cuando el gobierno republicano solicitó la mediación británica para negociar con Franco una rendición que incluyese garantías contra represalias indiscriminadas y autorización para exilarse a los republicanos que lo desearan. Londres aceptó únicamente actuar como transmisor de la propuesta republicana, negándose a presionar a Franco para que la aceptara o a asumir ninguna responsabilidad sobre el cumplimiento de las garantías ${ }^{48}$. Finalmente, el 27 de febrero de 1939, el gabinete británico, a la par que el francés, reconoció formalmente al gobierno franquista. El desahucio de la República estaba consumado. Ni siquiera el golpe del coronel Casado modificó la negativa británica a actuar como mediador en las negociaciones de ren-

\footnotetext{
${ }^{46}$ Acta del Comité de Política Exterior, 23-1-1939. CAB 27/624. Dentro del Foreign Office hubo notable oposición a Vansittart, basándose en el peligro de una victoria republicana. EI 7 de enero, un memorándum de O'Malley, aprobado por Mounsey y Sargent, expuso así la razón: «Considero un grave error suponer que el gobierno Negrín continuaria con su moderación y disciplina una vez eliminada la inmediata necesidad militar que impusieron ambas medidas. No he estado en Barcelona pero tengo la impresión de que, en España, las fuerzas de la indisciplina, anarquia, extremismo y jacquerie son extensas, antiguas y fuertes. Y creo que harian imposible la supervivencia del tipo de régimen que Negrín dice concebir para después de la derrota o desplome de los Blancos. La guerra continúa por la misma razón por la que empezó. Y empezó porque un gobierno civil de Frente Popular se desintegró y abrió paso a una extensa jacquerie. Franco y sus amigos no vieron la manera de frenarla y, de hecho, era evidente que no había otra manera excepto con un golpe militar». FO $371 / 24147$ W1415.

${ }^{47}$ Acta del gabinete, 8-11-1939. CAB 23/97. Telegramas del cónsul en Palma (25 y 31-1); informe del comandante del buque «Devonshire» (12-II-1939). FO 371/24146 W1404, W1857 y W6132.

${ }^{43}$ Telegramas de Lord Halifax al encargado de negocios ante la República y al agente en Burgos, 14 y 27-11-1939. FO 425/416.
} 
dición, pese a la simpatia con que fue recibido. De hecho, sectores influyentes del Foreign Office consideraron que la resistencia encontrada por Casado demostraba «que el general Franco ha estado realmente luchando contra el comunismo en España» ${ }^{49}$. Solamente tras la rendición incondicional de fines de marzo, Londres aceptó que la Royal Navy recogiera en Gandía a dos centenares de dirigentes republicanos, entre ellos Casado, y les concedió asilo en Gran Bretaña.

El final de la guerra no eliminó las inquietudes británicas respecto a España. Aún antes de que hubiese terminado, Hitler habia invadido lo que restaba de Checoslovaquia y Franco habia firmado el Pacto Anti-Comintern. Pocos dias después, Mussolini ocupaba Albania. En ese contexto, el Foreign Office reconoció su fracaso en el cumplimiento de uno de los objetivos establecidos como esenciales al comienzo del conflicto: garantizar, como minimo, la neutralidad estricta de España en caso de guerra europea. En el informe sobre la situación europea elaborado a mediados de abril de 1939, el Foreign Office recomendó a los Jefes de Estado Mayor que planificasen la defensa imperial sobre el supuesto de que España "será neutral, pero interpretará su neutralidad en un sentido fuertemente favorable al Eje» $y$ "pudiera ser que se uniese al enemigo como beligerante " ${ }^{50}$. Hasta el comienzo de la guerra mundial, la incertidumbre y el temor continuaron siendo los elementos claves en las apreciaciones británicas sobre la España franquista. Paralelamente, la fe en la diplomacia de la libra para garantizar esa neutralidad hispana fue sustituida por la confianza en el efecto paralizante del cansancio y destrucción provocados por la guerra y del temor a la capacidad anglo-francesa de bloqueo naval y ocupación de la colonia marroqui ${ }^{51}$. Cuando finalmente estalló la guerra europea y la neutralidad franquista se reveló tan malévola como se habia previsto, Vansittart redactó el siguiente epitafio sobre la política británica en la guerra civil:

Esta siempre fue la consecuencia inevitable de una victoria de Franco; a su vez, la consecuencia inevitable del cierre de la frontera francesa

${ }^{49}$ Minuta de Mounsey al memorándum de Mr. Cowan sobre el final de la guerra civil en Madrid, 19-IV-1939. FO 371/24129 W5827. Sobre los rumores de que Casado actuó con apoyo británico a través de Cowan, compario la tesis negativa de ALPERT, M. El Ejército republicano en la guerra civil (2. ${ }^{a}$ ed., Madrid 1989), págs. 278 y ss.

${ }^{50}$ Informe politico para el Comité de Defensa Imperial, 17-IV-1939. FO 371/23743 R3989.

51 Junta de Jefes de Estado Mayor: Nota sobre el efecto probable del bloqueo de todas las importaciones maritimas de España sobre su potencia y resistencia armada en caso de guerra, 13-V. CAB 53/49. Memorándum de Mr Roberts, 19-V. FO 371/24159 W8087. Informe del comandante Mahony, 26-VI. FO 371/24131 W11396. Acta del gabinete, 26-VIl-1939. CAB $23 / 100$. 
y de toda la farsa partidista de la No Intervención. Yo nunca entendí cómo podía esperarse que dicha política tuviera un resultado distinto del que ahora contemplamos ${ }^{52}$.

En definitiva, antes de que se llegara al Anschluss y a Munich, la guerra civil había servido como escenario principal de aplicación de la política de apaciguamiento y, a la par, se habia ido convirtiendo en el campo de prueba privilegiado de su viabilidad. La única diferencia con los dos casos citados, pero una diferencia esencial para infortunio de la República española, fue que la prevención antirrevolucionaria siguió operando en los análisis y decisiones de las autoridades británicas hasta la extinción del conflicto. De no contar este factor político-ideológico, resulta incomprensible el grado de pasividad inhibitoria mostrado frente a los riesgos político-estratégicos que fueron surgiendo para la seguridad de un área vital en la defensa del Imperio. Sin duda, el sacrificio de una España «roja» fue juzgado un precio razonable por la codiciada amistad italiana y la ilusión de preservar la paz europea y, en consecuencia, el gobierno británico «tomó agua y se lavó las manos».

${ }^{52}$ Minuta, 20-X-1939. FO 371/23168 C16669. 